\title{
BMJ Open Associations between effort-reward imbalance and health indicators among school teachers in Chuquisaca, Bolivia: a cross-sectional study
}

\author{
Maria Teresa Solis-Soto, ${ }^{1,2}$ Anabel Schön, ${ }^{3}$ Manuel Parra, ${ }^{3}$ Katja Radon ${ }^{3}$
}

To cite: Solis-Soto MT, Schön A, Parra $\mathrm{M}$, et al. Associations between effort-reward imbalance and health indicators among school teachers in Chuquisaca, Bolivia: a crosssectional study. BMJ Open 2019;9:e025121. doi:10.1136/ bmjopen-2018-025121

- Prepublication history and additional material for this paper are available online. To view these files, please visit the journal online (http://dx.doi org/10.1136/bmjopen-2018025121).

Received 29 June 2018 Revised 3 December 2018 Accepted 22 January 2019

Check for updates

(c) Author(s) (or their employer(s)) 2019. Re-use permitted under CC BY-NC. No commercial re-use. See rights and permissions. Published by BMJ.

${ }^{1}$ Instituto de Ciencias de la Salud, Universidad de 0'Higgins, Rancagua, Chile

${ }^{2}$ Doctoral Academic Committee, Universidad San Francisco Xavier de Chuquisaca, Sucre, Bolivia

${ }^{3}$ CIHLMU@0ccupational Social and Environmental Medicine, Klinikum der Universitat Munchen, Munich, Bayern, Germany

Correspondence to

Dr Maria Teresa Solis-Soto; maritesolissoto@gmail.com

\section{ABSTRACT}

Objective To assess the association between effortreward imbalance (ERI) and health indicators among Bolivian school teachers.

Design School-based cross-sectional study. Setting Sixty randomly selected schools from rural (33) and urban (27) schools in Chuquisaca, Bolivia.

Participants A total of 1062 school teachers were invited to participate, of which 597 answered the questionnaire (response 56.2\%).

Exposure measure Psychosocial factors at work were explored through the short version of the Effort-Reward Questionnaire.

\section{Primary and secondary outcome measures Health} outcomes included self-rated overall health, mental distress (12-item General Health Questionnaire $\geq 5$ ) and the 7-day prevalence of low back pain (LBP) as well as neck or shoulder pain (Nordic Questionnaire). Crude and adjusted ORs and their $95 \%$ Cls for each health outcome were calculated using logistic regression models.

Results The median value for the effort-reward ratio was 0.91 (range: 0.3-2.3) with higher values for teachers from rural versus urban schools. Overall, about $43 \%$ of the teachers reported their overall health as fair or poor; $45 \%$ suffered mental distress, $17 \%$ reported LBP and $29 \%$ neck or shoulder pain. Prevalences were higher for teachers employed at rural schools compared with those at urban schools. After adjusting for potential confounders and school location, ERI was statistically significantly associated with fair/poor self-rated health (adjusted OR $1.7,95 \% \mathrm{Cl} 1.0$ to 2.9$)$; mental distress $(1.9 ; 95 \% \mathrm{Cl} 1.2$ to $3.1)$ and $\operatorname{LBP}(2.3 ; 95 \% \mathrm{Cl} 1.3$ to 4.1$)$.

Conclusion Our results indicate the urgent need to improve psychosocial working conditions among Bolivian school teachers, in order to promote their health and wellbeing.

\section{BACKGROUND}

School teachers are exposed to high and multiple emotional and physical demands inside and outside the classroom. ${ }^{1}$ This includes a variety of tasks: high workload, large class sizes, bad behaviour of students, negative organisational climate, problems with school authorities, lack of autonomy,

\section{Strengths and limitations of this study}

- The study explores the role of psychosocial working conditions on the health of teachers, an aspect rarely studied in low-income countries.

- We used validated questionnaires to measure exposure and outcome.

- Due to limited resources, no diagnostic evaluations for any of the health outcomes included could be done.

- Limited external validity by exclusion of schools (in remote and dispersed rural areas)

lack of motivation, low social status and scarce social support. ${ }^{2}$ For that reason, teaching is considered a stressful profession. ${ }^{3-5}$ As a consequence, high rates of absenteeism and early retirement were reported among teachers. ${ }^{6}$ Among the negative consequences of teaching on health and well-being, fatigue, headaches, tension, listlessness, sleep and concentration disorders, inner restlessness and increased irritability were reported. ${ }^{5}$

From teachers and other professions, it is well known that psychosocial factors at work play an important role in the development of work stress. ${ }^{78}$ Among the explanatory models for this association, Siegrist proposed the effort-reward imbalance at work (ERI) model. This approach is based on the conception of 'social reciprocity'. ${ }^{9}$ It means that every employee expects fair rewards for his/ her efforts. Rewards could be reflected in perceived esteem, career opportunities and job security. Considering this, the ERI model assumes that an absent or inadequate reciprocity could result in emotional distress, and therefore, adverse health effects. Previous studies and systematic reviews reported that ERI is related to increased risk of poor work ability, ${ }^{10}$ poor self-rated health, ${ }^{11}{ }^{12}$ mental disorders, ${ }^{313}$ cardiovascular diseases ${ }^{14} 15$ and musculoskeletal diseases especially affecting 
low back and neck or shoulders. ${ }^{16}{ }^{17}$ Additionally, this model proposes that personal characteristics like an excessive work-related commitment (overcommitment [OC]) or the interaction between OC and ERI could affect workers' health. ${ }^{18}$

Very little information is available about teachers' working conditions and health in Latin America. A multicentre study among teachers from Argentina, Chile, Ecuador, Mexico, Peru and Uruguay reported that their work in these countries is characterised by work overload, little time to rest and high extracurricular work. ${ }^{19}$ Additionally, the authors found a high percentage of health problems related to a strained voice, uncomfortable postures, high mental work demands, social problems related to the students (eg, parental neglect, domestic violence and poverty), deficient infrastructure and lack of teaching material. Most of the teachers perceived low appreciation of their work by society. ${ }^{19}$ This latter finding was also reported for Bolivian teachers. ${ }^{20}$ Other studies in Latin America and Africa likewise found unsuitable working conditions among teachers, ${ }^{21-25}$ with marked differences between work in rural and urban areas, described in terms of living conditions and in terms of teachers' work.

In Bolivia, one of the largest public workforces (179689 workers) is composed of teachers and administrative staff working in the educational sector; of these, $58.2 \%$ are women, and $79 \%$ work in urban areas. ${ }^{26}$ Teachers with formal contracts have to teach between 72 and 160 hours per month. In addition, it is very common for teachers to work in more than one school, for example, in different shifts (morning, afternoon or evening) or at public and private schools. ${ }^{27}$ The number of students per teacher is high, especially at secondary level (about 41 students per teacher) and in the urban areas (about 37 students per teacher). This imbalanced ratio has only grown in recent years as a result of policies which incentivise students to stay in school longer. ${ }^{27}$

In a previous publication, we reported a high percentage of musculoskeletal disorders (MSDs) among Bolivian teachers. The prevalence of musculoskeletal pain in any part of the body was $86 \%$ during the last 12 months, $63 \%$ during the last 7 days and $15 \%$ for work-limiting pain. ${ }^{28}$ Besides this study, we are not aware of any other study among Bolivian teachers assessing psychosocial work environment and health. In this context, the objective of this study was to assess the association between ERI and health indicators among Bolivian school teachers working in rural and urban areas. Further, we want to assess the association between the ERI and health indicators regardless of gender, age or place of work. In this way, the results of this study will support the still lacking establishment of public health prevention policies and surveillance programmes among Bolivian teachers.

\section{METHODS}

From August to November 2015, a cross-sectional study was conducted among school teachers working in regular education in Chuquisaca, Bolivia. Chuquisaca is one of the nine main regions in Bolivia, located in the Southern central part of the country, with a surface area of approximately $51524 \mathrm{~km}^{2}, 576153$ inhabitants ${ }^{29}$ and a Regional Human Development Index of $0.674 .{ }^{30}$

From the register of the regional education department, 60 schools from the regular education system were selected randomly, and all teachers were invited to participate in the study (1062 teachers), independent of their type of contract or their number of working hours. Of these schools, 27 schools were located in urban areas and 33 in rural areas. Small schools (less than five teachers) were excluded a priori because of difficult geographical access. Approximately $14 \%$ of all teachers in Chuquisaca work in such small schools.

The study team visited the selected schools and asked the director to distribute an envelope containing the questionnaire, information sheet and informed consent form to all teachers working in the school. In each of the schools, two boxes were installed-one to collect the completed anonymous questionnaires, the other to collect the informed consent form. Teachers were asked to place the completed questionnaire and the signed informed consent form into the different boxes, which 1 week later were picked up from the school by the research team.

In order to find statistically significant differences between rural and urban school, we aimed for a minimum sample size of 480 teachers (240 per geographical area) in order to reach a statistical power of $80 \%$ at an alpha of 0.05 for an outcome prevalence of $50 \%$.

\section{Instruments and variable definitions}

The paper-pencil questionnaire consisted of 65 closed questions (16 pages) and took approximately $30 \mathrm{~min}$ to complete. Teachers completed the questionnaire during their free time at the schools or at home. Teachers did not receive any type of direct incentive for their participation in the study.

Sociodemographic variables and working conditions were explored through the VI. National Survey of Working Conditions and Health (Spain) ${ }^{31}$ and the Unesco study on working conditions and health in teachers. ${ }^{19}$ They included: age (assessed in four categories: $\leq 29,30-39$, $40-49$ and $\geq 50$ years, but subsequently recategorised into two groups: $<40$ years, $\geq 40$ years, based on the distribution of the variable), gender (male and female) and school location (rural and urban). Teaching level was grouped into exclusive primary, primary and secondary, and exclusive secondary. Hours per week spent in extracurricular activities (carried out outside the school) included: preparing school lessons, preparing teaching material, preparing extraprogramme activities, meeting with parents or pupils, planning and team working, administrative duties, participating in courses and correcting class tests. Teachers were asked to report the number of 
hours per week they regularly spend for each of these activities. Later, this variable was dichotomised at the median value ( $<10$ and $\geq 10$ hours/week). Finally, monthly income was explored taking as reference the minimum wage for Bolivia. It was grouped in: low (<US\$238: less than the minimum wage), medium (US\$239-US\$476: between $100 \%$ and $200 \%$ of the minimum wages) and high (>US\$476: more than double the minimum wage).

\section{Effort-reward imbalance and overcommitment}

ERI and OC were assessed using the Spanish short version of the ERI questionnaire, ${ }^{32}$ which has been widely used in Latin American countries. ${ }^{33}$ It included three effort items, seven reward items and six items to evaluate OC. Efforts are related to the demands of the work environment (quantitative and qualitative load, and increase in workload over time) while rewards refer to aspects related to esteem, promotion and job security. ${ }^{9}$ Each item was measured on a 4-point Likert scale (1=strongly disagree, $2=$ disagree, $3=$ agree and $4=$ strongly agree). Following the recommendations for the construction of the score ${ }^{32}$ the ERI ratio was computed dividing effort score (enumerator) with reward score (denominator) and multiplying by $7 / 3$ to adjust for the unequal number of effort and rewards items. As recommended by Siegrist $e t a l,{ }^{32}$ the study populations' distribution was used to dichotomise ERI considering teachers with values in the highest tertile as a risk group. In our study, this corresponds to a ratio greater than 1 (greater effort than perceived reward).

The OC scale was computed by summing up all items. It was dichotomised considering people with values in the highest tertile $(\mathrm{OC}>17)$ as a high OC group.

\section{Outcomes}

Self-rated overall health was assessed on a 5-point Likert scale from excellent to poor through the 36-item Short Form Survey (SF-36) item 'How do you rate your health?' ${ }^{34}$ Poor or fair overall health was considered if participants reported their self-reported health to be poor or fair. ${ }^{35}$

The Spanish version of the 12-item General Health Questionnaire (GHQ-12) was used to explore psychological distress during the previous 4 weeks. ${ }^{36}$ Each question was rated on a 4-point Likert scale (from 'much more than usual' to 'not at all'. Following the 0-0-1-1 scaling method, the resulting score ranged from 0 to 12 points with higher scores meaning a higher level of mental distress. Due to lack of a validated cut-off for Bolivia, we used the Chilean and Argentinian cut-off of $\geq 5$ to define teachers with mental distress. ${ }^{36} 37$

MSDs were explored using the Spanish version of the Standardised Nordic questionnaire. The questionnaire includes an anatomical depiction of different parts of the body. ${ }^{38}$ With the help of this depiction, respondents identify pain areas where they experienced pain during the last 12 months, and if so, they are asked about pain during the last 7 days and work-limiting pain during the 12 months prior to the study. For this study, we considered 7-day prevalence to define pain in the neck or shoulder (neck/shoulder pain) and low back pain as a proxy for chronic or recurring pain.

\section{Data analysis}

Questionnaires were double entered into EpiInfo V.7 for Windows. After a congruence check, data were exported to IBM SPSS Statistics V.24 for further analysis. All the numerical variables included in the study (Effort-Reward Scales, extracurricular activities and GHQ-12 score), did not follow a normal distribution, so the median and range were reported. For categorical variables, absolute and relative frequencies were calculated for the total population. Working conditions and health indicators for teachers who worked in urban and rural areas were compared using a $\chi^{2}$ test (categorical variables).

After an analysis of the pattern of incomplete data, missing at random mechanism was assumed, and missing values were replaced via multiple imputation by fully conditional specifications. ${ }^{39}$ In total, 10 imputation data sets were created using logistic regression equations as the imputation method (categorical variables). Combining those, logistic regression models were used to calculate crude and adjusted ORs, as well as their corresponding 95\% CIs for the four health outcomes. Based on previous studies ${ }^{3717}$ and the bivariate analyses, models were adjusted for age, gender, school location, teaching level, type of school, hours per week spent in extracurricular activities and income. Interactions between ERI and OC were tested. As a sensitivity analysis, we performed complete cases analysis.

\section{Ethics approval and consent to participate}

In order to protect the rights and well-being of participants, international ethical recommendations for research with human beings ${ }^{40}$ were followed. An information letter, as well as a written informed consent form, was provided to each participant. The questionnaire was completely anonymous and voluntary participation was respected at all times.

\section{Patient and public involvement}

No patients/public were involved in the development of the research question, design or implementation of the study. Dissemination of the results of the study was made available to the health and education authorities and a summary of the study was sent to each participating school.

\section{RESULTS}

A total of 620 teachers returned the questionnaire (response $56.2 \%$ ), 356 by teachers working in rural areas and 264 in urban areas. For the analyses presented in this paper, 23 questionnaires were excluded because participants were administrative staff $(n=19)$, or only completed the first page of the questionnaire (4). 
Table 1 Sociodemographic and work-related characteristics of study population in teachers working in rural and urban areas $(n=597)$

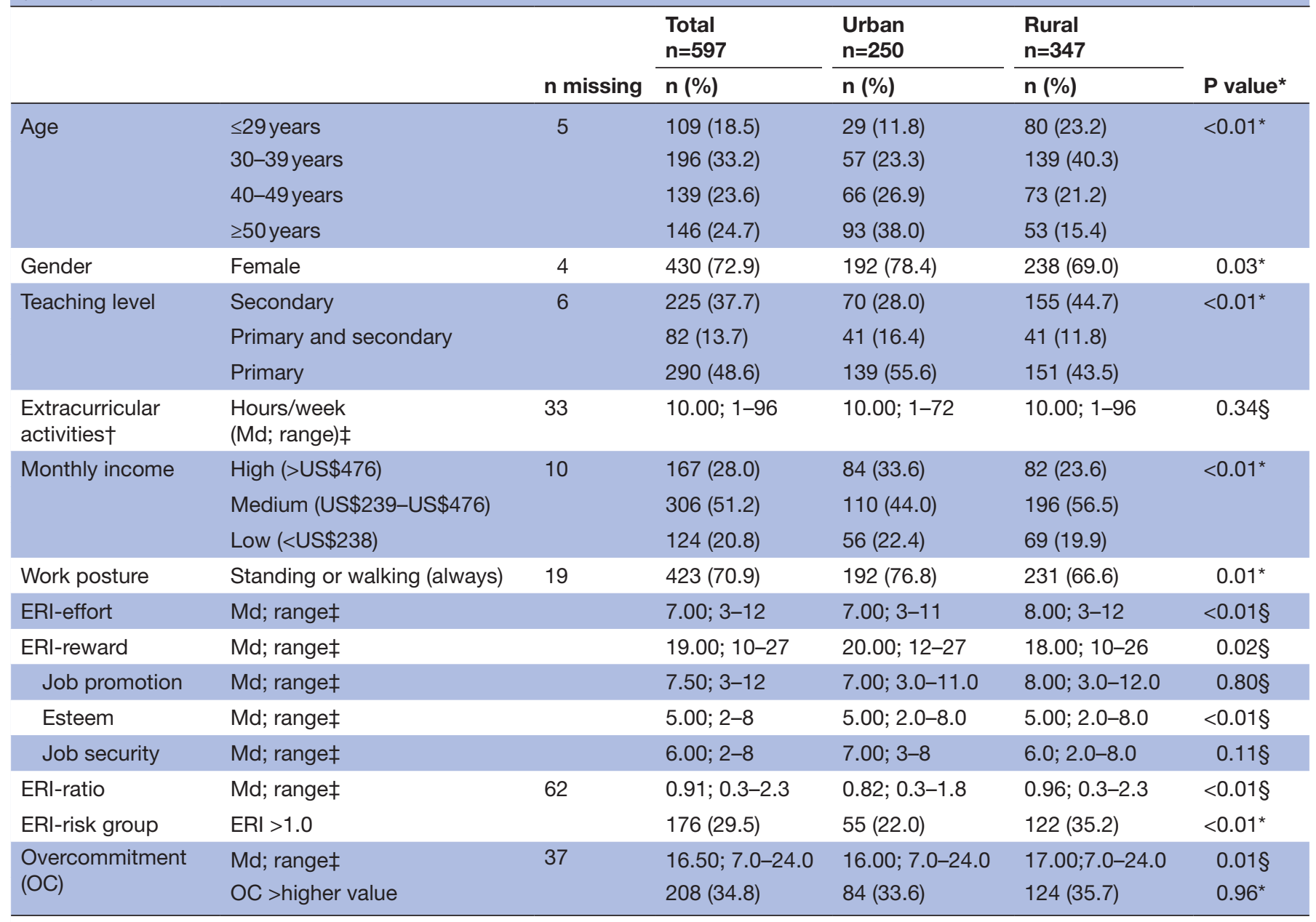

${ }^{*} \mathrm{P}$ value $\chi^{2}$ test.

†Extracurricular activities: the sum of time in extracurricular activities including preparing school lessons, preparing teaching material, preparation of extraprogramme activities, interviews with parents or pupils, planning and teamwork, administrative duties, participation in courses and correcting class tests.

$\ddagger$ Md, median; range, minimum and maximum value.

$\S P$ value Mann-Whitney U test.

$\mathrm{ERI}$, effort-reward imbalance.

\section{Sociodemographic and work-related characteristics of urban and rural teachers}

Teachers working in urban areas were statistically significantly older, were more likely to be female, work at the primary level, have high income and always walk or stand while working compared with teachers working in rural areas. There were no statistically significant differences between teachers working in rural and urban areas for extracurricular activities (table 1 ).

Median values for effort-reward Ratio showed higher reward in comparison to the effort (median 0.91; range: $0.3-2.3$ ) in both groups, even though the median value for teachers working in rural areas was less favourable than those in urban areas $(0.96$ vs $0.82 ; \mathrm{p}<0.01)$ (table 1$)$. Likewise, the prevalence of teachers reporting ERI $>1$ was higher in teachers working in rural areas $(35 \%)$ compared with those employed in urban areas $(22 \%$; $\mathrm{p}<0.01)$.

\section{Health indicators}

In general, a high percentage of teachers perceived their health as being fair or poor with higher prevalences among teachers working in rural areas (50\%) compared with urban areas $(28 \% ; \mathrm{p}<0.001)$. Likewise, the median value of the sum of the GHQ-12 score was significantly higher in teachers working in rural areas compared with their counterparts ( 4.0 vs $5.0 ; \mathrm{p}<0.01$ ). Applying a GHQ-12 score of 5 or above as a cut-off point to consider mental distress, more than half of the teachers in rural areas $(51 \%)$ and $38 \%$ of those in urban areas were affected. Musculoskeletal pain during the last 7 days was reported by $29 \%$ of the teachers for neck or shoulder pain and by $17 \%$ for low back pain, without statistically significant differences between teachers employed at rural or urban schools (table 2). 
Table 2 Health indicators study population in teachers working in rural and urban areas $(n=597)$

\begin{tabular}{|c|c|c|c|c|c|c|}
\hline & & & $\begin{array}{l}\text { Total } \\
\mathrm{n}=597\end{array}$ & $\begin{array}{l}\text { Urban } \\
\mathrm{n}=250\end{array}$ & $\begin{array}{l}\text { Rural } \\
\mathrm{n}=347\end{array}$ & \\
\hline & & n missing & n (\%) & n (\%) & n (\%) & $P$ value \\
\hline Excellent & & 5 & $16(2.7)$ & $10(4.1)$ & $6(1.8)$ & $<0.001 \dagger$ \\
\hline Very good & & & $67(11.2)$ & $36(14.7)$ & $30(8.7)$ & \\
\hline Poor & & & $16(2.7)$ & $1(0.4)$ & $15(4.2)$ & \\
\hline Mental health $\ddagger$ & & & & & & \\
\hline GHQ-12 score (Md; range)§ & & 70 & $4.00 ; 0.0-12.0$ & $4.00 ; 0.0-11.0$ & $5.00 ; 0.0-12.0$ & $<0.019$ \\
\hline Mental distress (GHQ-12 values $\geq 5$ ) & & & $271(45.4)$ & $94(37.6)$ & $177(51.0)$ & $0.02 \dagger$ \\
\hline
\end{tabular}

*Question of the SF-36 questionnaire: 'How do you rate your health?'

†P value $\chi^{2}$ test.

¥Spanish version of the 12-item General Health Questionnaire (GHQ-12).

$\S M d$, median; range, minimum and maximum value.

IP value Mann-Whitney $U$ test.

${ }^{\star *}$ Explored with the Spanish version of the Standardised Nordic questionnaire.

\section{Logistic regression models for health indicators}

In the univariate model, teachers with ERI scores $>1$ compared with those with lower scores were statistically significantly more likely to self-rate their overall health as fair or poor (crude OR 1.9; 95\% CI 1.2 to 2.9), to suffer from mental distress $(2.0 ; 95 \%$ CI 1.3 to 3.0$)$, to report low back pain $(2.4 ; 95 \%$ CI 1.4 to 4.0$)$ and neck or shoulder pain (1.7; 95\% CI 1.1 to 2.7). After adjustment, the results remained consistent. However, they were no longer statistically significant for neck or shoulder pain. Independently of the other variables, women (as opposed to men) and those working in rural areas (as opposed to urban areas) were more likely to report worse health indicators (tables 3 and 4 ). The results were consistent with the case complete analysis (see online supplementary additional tables). The ERI and OC interaction did not show association with any health indicator, therefore, the interaction term was not included in the final models.

\section{DISCUSSION}

This paper aimed to compare working conditions and health indicators in teachers working in rural and urban areas, and to assess the association between psychosocial work environment and health outcomes in school teachers from Chuquisaca-Bolivia. Our results showed a high prevalence of teachers who perceived their overall and mental health as low. Likewise, a considerable proportion of teachers reported neck/shoulder pain or low back pain. Psychosocial working conditions measured by ERI were an important predictor of all outcomes except neck/shoulder pain. The intrinsic factor OC did not explain this association, nor was an effect modification by OC indicated.

\section{Health outcomes}

While there is little information available on the prevalence of self-rated overall health in teachers, data for the general adult population in Latin America indicate a high variability between and within countries. For example, one study carried out in multiple Latin American countries found a prevalence of self-reported health rated as poor among $22 \%$ of people in Uruguay and $49 \%$ in Brazil. ${ }^{41}$ In comparison, the prevalence among our study population could be considered relatively high $(43 \%)$.

With respect to mental distress, the prevalence in our study $(45.4 \%)$ was higher than the one reported previously in German teachers (26.2\%), ${ }^{342}$ and quite similar to the one reported in Japanese teachers $(47.3 \%)$. However, the latter study applied a lower GHQ-12 cut-off point $(\geq 4) .{ }^{43}$ Applying this cut-off point to our study population, the prevalence of distress would have been $58 \%$ and thus higher than among Japanese teachers.

\section{Comparison between teachers working in urban and rural areas}

In our study, teachers working in rural areas were more likely to perceive their health as fair or poor, to report a higher percentage of mental distress and to suffer from musculoskeletal pain than teachers from urban areas. These differences could be partially explained 
Table 3 Crude and adjusted logistic regression analyses for self-rated overall health and mental distress among 597 Bolivian teachers using multiple imputation

\begin{tabular}{|c|c|c|c|c|c|c|}
\hline & \multicolumn{3}{|c|}{ Self-rated health (fair or poor) ${ }^{\star}$} & \multicolumn{3}{|c|}{ Mental distress $\dagger$} \\
\hline & n (\%) & OR $(95 \% \mathrm{Cl})$ & aOR $(95 \% \mathrm{Cl}) \ddagger$ & n (\%) & OR $(95 \% \mathrm{Cl})$ & aOR $(95 \% \mathrm{Cl}) \ddagger$ \\
\hline \multicolumn{7}{|l|}{ Age } \\
\hline$<40$ years & $146(47.4)$ & 1 & 1 & $153(49.7)$ & 1 & 1 \\
\hline$\geq 40$ years & $114(39.4)$ & $0.72(0.5$ to 1.0$)$ & 0.88 (0.6 to 1.3$)$ & $118(40.8)$ & $0.11(0.5$ to 1.1$)$ & 0.85 (0.5 to 1.4$)$ \\
\hline \multicolumn{7}{|l|}{ Gender } \\
\hline Male & $56(33.5)$ & 1 & 1 & $69(41.3)$ & 1 & 1 \\
\hline Female & $204(47.4)$ & 1.80 (1.2 to 2.6$)$ & 2.06 (1.3 to 3.2$)$ & $202(47.0)$ & 1.25 (0.8 to 1.9$)$ & $1.24(0.8$ to 2.0$)$ \\
\hline \multicolumn{7}{|l|}{ Place of work } \\
\hline Urban & $71(28.4)$ & 1 & 1 & $94(37.6)$ & 1 & 1 \\
\hline Rural & $189(54.5)$ & 3.01 (2.1 to 4.3$)$ & 3.62 (2.4 to 5.5$)$ & $177(51.0)$ & 1.71 (1.1 to 2.6$)$ & 1.58 (1.0 to 2.4$)$ \\
\hline \multicolumn{7}{|l|}{ Teaching level } \\
\hline Secondary & $88(39.1)$ & 1 & 1 & $97(43.1)$ & 1 & 1 \\
\hline Primary and secondary & $28(34.1)$ & 0.80 (0.5 to 1.4$)$ & 1.05 (0.6 to 2.0$)$ & $34(41.5)$ & 0.94 (0.5 to 1.6$)$ & 1.16 (0.6 to 2.2$)$ \\
\hline Primary & $144(49.7)$ & 1.53 (1.1 to 2.2$)$ & 1.80 (1.2 to 2.7$)$ & $140(48.3)$ & $1.22(0.8$ to 1.9$)$ & 1.46 (0.9 to 2.3$)$ \\
\hline \multicolumn{7}{|l|}{ Extracurricular activities§ } \\
\hline$\leq 10$ hours per week & $146(45.5)$ & 1 & 1 & $145(44.6)$ & 1 & 1 \\
\hline$>10$ hours per week & $114(41.9)$ & 0.88 (0.6 to 1.3$)$ & $0.76(0.5$ to 1.1$)$ & $126(46.3)$ & 1.08 (0.7 to 1.6$)$ & $1.00(0.7$ to 1.5$)$ \\
\hline \multicolumn{7}{|l|}{ Monthly income } \\
\hline High (>US\$476) & $69(41.6)$ & 1 & 1 & $69(41.6)$ & 1 & 1 \\
\hline $\begin{array}{l}\text { Medium (US\$239- } \\
\text { US\$476) }\end{array}$ & $52(41.6)$ & 1.01 (0.6 to 1.6$)$ & 0.81 (0.5 to 1.3 ) & $53(42.4)$ & 1.03 (0.5 to 2.0$)$ & 0.93 (0.4 to 2.2$)$ \\
\hline Low (<US\$238) & $139(45.4)$ & 1.17 (0.8 to 1.7$)$ & 0.80 (0.4 to 1.3$)$ & $149(48.7)$ & 1.34 (0.8 to 2.3$)$ & 1.12 (0.6 to 2.1$)$ \\
\hline \multicolumn{7}{|c|}{ Work posture (standing or walking) } \\
\hline Never-most of the time & $69(39.7)$ & 1 & 1 & $86(49.4)$ & 1 & 1 \\
\hline Always & $191(45.2)$ & 1.26 (0.9 to 1.8$)$ & 1.48 (1.0 to 2.2$)$ & $187(44.2)$ & 0.81 (0.5 to 1.3$)$ & 0.81 (0.5 to 1.4$)$ \\
\hline \multicolumn{7}{|l|}{ ERI } \\
\hline$\leq 1$ & $164(39.0)$ & 1 & 1 & $171(40.6)$ & 1 & 1 \\
\hline$>1$ & $96(54.5)$ & 1.85 (1.2 to 2.9$)$ & 1.74 (1.0 to 2.9$)$ & $101(57.4)$ & 1.96 (1.3 to 3.0$)$ & 1.91 (1.2 to 3.1$)$ \\
\hline \multicolumn{7}{|l|}{ Overcommitment } \\
\hline$\leq$ Low/medium value & $145(37.2)$ & 1 & 1 & $161(41.3)$ & 1 & 1 \\
\hline >Higher value & $114(54.8)$ & 2.10 (1.3 to 3.5$)$ & 1.84 (1.1 to 3.2$)$ & $110(52.9)$ & 1.61 (1.0 to 2.5$)$ & 1.40 (0.8 to 2.3$)$ \\
\hline
\end{tabular}

*Question of the SF-36 questionnaire: 'How do you rate your health?'.

†Spanish version of the 12-item General Health Questionnaire.

łaOR 95\% Cl: adjusted OR and 95\% Cl.

$\S$ Extracurricular activities: the sum of time in extra-curricular activities including preparing school lessons, preparing teaching material, preparation of extra-programme activities, interviews with parents or pupils, planning and teamwork, administrative duties, participation in courses and correcting class tests.

ERI, effort-reward imbalance.

by demographic variables, socioeconomic status and availability of healthcare resources across countries and cultures. $^{44} 45$

In Bolivia, a teaching career in public schools frequently starts in rural areas. With a job promotion, teachers may then change to an urban school after their first years on duty. This explains the younger age and lower income of the teachers working at rural schools observed in our study.
For many young teachers, this means living away from their families and friends at the beginning of their career in a cultural setting where family and friends are more important than in many high-income countries. Given the infrastructure in Bolivian rural areas, the travel time from school to home town might be long, only permitting rare visits home during the school year. In addition, the low salary of school teachers in Bolivia (every fifth teacher 
Table 4 Crude and adjusted logistic regression analysis for 7-day prevalence of low back pain and neck/shoulder pain among 597 Bolivian teachers using multiple imputation

\begin{tabular}{|c|c|c|c|c|c|c|}
\hline & \multicolumn{3}{|c|}{ 7-day prevalence of low back pain* } & \multicolumn{3}{|c|}{ 7-day prevalence of neck or shoulder pain* } \\
\hline & n (\%) & OR (95\% Cl) & aOR $(95 \% \mathrm{Cl}) \dagger$ & n (\%) & OR $(95 \% \mathrm{Cl})$ & aOR $(95 \% \mathrm{Cl}) \dagger$ \\
\hline \multicolumn{7}{|l|}{ Age } \\
\hline$\geq 40$ years & $38(13.1)$ & $0.56(0.4$ to 0.9$)$ & $0.62(0.4$ to 1.0$)$ & $70(24.2)$ & $0.62(0.4$ to 0.9$)$ & 0.77 (0.5 to 1.2$)$ \\
\hline \multicolumn{7}{|l|}{ Gender } \\
\hline Female & $80(18.6)$ & 1.36 (0.8 to 2.3$)$ & 1.37 (0.8 to 2.4$)$ & $139(32.3)$ & 1.77 (1.2 to 2.7$)$ & $1.80(1.1$ to 2.9$)$ \\
\hline \multicolumn{7}{|l|}{ Place of work } \\
\hline Urban & $40(16.0)$ & 1 & 1 & $65(26.0)$ & 1 & 1 \\
\hline Rural & $64(18.4)$ & 1.19 (0.8 to 1.8$)$ & $0.88(0.5$ to 1.4$)$ & $109(31.4)$ & $1.30(0.9$ to 1.9$)$ & $1.12(0.7$ to 1.7$)$ \\
\hline \multicolumn{7}{|l|}{ Teaching level } \\
\hline \multicolumn{7}{|l|}{ Extracurricular activities $\ddagger$} \\
\hline$\leq 10$ hours per week & $57(15.5)$ & 1 & 1 & $87(26.8)$ & 1 & 1 \\
\hline$>10$ hours per week & $48(17.6)$ & $1.01(0.7$ to 1.6$)$ & $0.86(0.5$ to 1.4$)$ & $87(32.0)$ & $1.29(0.9$ to 1.9$)$ & $1.15(0.8$ to 1.7$)$ \\
\hline \multicolumn{7}{|l|}{ Monthly income } \\
\hline High (>US\$476) & $24(14.5)$ & 1 & 1 & $39(23.5)$ & 1 & 1 \\
\hline $\begin{array}{l}\text { Medium (US\$239- } \\
\text { US\$476) }\end{array}$ & $20(16.0)$ & 1.09 (0.6 to 2.1) & 0.85 (0.4 to 1.8$)$ & $36(28.8)$ & 1.29 (0.8 to 2.2) & $1.02(0.6$ to 1.8$)$ \\
\hline Low (<US\$238USD) & $61(19.9)$ & 1.46 (0.9 to 2.5$)$ & 1.11 (0.6 to 2.0 ) & $99(32.4)$ & 1.54 (1.0 to 2.4$)$ & $1.18(0.7$ to 1.9$)$ \\
\hline \multicolumn{7}{|l|}{ Overcommitment } \\
\hline$\leq$ Low/medium value & $60(15.4)$ & 1 & 1 & $103(26.4)$ & 1 & 1 \\
\hline >Higher value & $44(21.2)$ & 1.52 (0.8 to 3.1$)$ & 1.34 (0.7 to 2.5$)$ & $71(34.1)$ & 1.46 (0.8 to 2.6$)$ & 1.29 (0.7 to 2.3$)$ \\
\hline
\end{tabular}

*Spanish version of the Standardised Nordic questionnaire. taOR 95\% Cl: adjusted OR and 95\% Cl.

†Extracurricular activities: the sum of time in extracurricular activities including preparing school lessons, preparing teaching material, preparation of extraprogramme activities, interviews with parents or pupils, planning and teamwork, administrative duties, participation in courses and correcting class tests.

ERI, effort-reward imbalance.

in our study only received the minimum wage) was even lower for rural teachers. Therefore, it is not surprising that rural teachers in our study perceived the relationship between effort and reward of their work as worse than their urban counterparts.

\section{Association between ERI and health indicators}

Our results confirm previous studies indicating that ERI might be a risk factor for health outcomes including self-rated overall health, ${ }^{46}$ low back pain ${ }^{47}$ and mental distress ${ }^{3}$ in different working populations. Self-rated health was described to be a good indicator of health status and mortality risk ${ }^{48}$ especially for women. ${ }^{49}$ Work-stress could lead to changes in the nervous system that condition the perception of one's own health or the start of a health problem. Falconer and Quesnel-Vallée ${ }^{50}$ demonstrated with a nationally representative longitudinal study in Canada that health information and acknowledgement of their 
disease diagnoses influence subjective health in an important way.

Similarly, our results indicate an association between ERI and mental distress, ${ }^{72}$ independent of socioeconomic and working characteristics. Although it was proposed that an interaction between ERI and OC could affect the association between ERI and physical and mental health, ${ }^{18}$ our results are consistent with other studies which do not confirm such effect modification by OC. ${ }^{51}$ This means that the association between psychosocial work environment and health in our population of rural and urban teachers is not modified by the intrinsic factor of OC to work.

Several studies have previously reported a relationship between a poor psychosocial work environment and MSDs in school teachers. ${ }^{52}$ This relationship could potentially be explained by the variety of job functions they perform inside and outside the classroom apart from the demands of family life. According to Bugajska et $a \tilde{l}^{3}$ ' adverse psychosocial work factors increase physical load'. In this sense, high job demands could be related to long working hours, few breaks at work and infrequent changes in posture. As reported in other studies, our results showed a weak association between psychosocial factors at work and neck or shoulder pain during the last 7 days, ${ }^{4754}$ probably due to the effect of other variables not considered in the study.

\section{Strengths and limitations of the study}

This is the first study in Bolivia in which employment and working conditions were studied as potential risk factors for physical and mental health conditions in school teachers working in rural and urban areas. For this, we used validated and standardised questionnaires to measure our main variables in order to compare our findings to other studies around the world. The ERI questionnaire was recognised as a good tool to assess psychosocial risk at work ${ }^{51}$ and to predict burn-out as the consequence of incompatibilities between professionals and their job contexts. ${ }^{55}$ Self-rated health is reported as a validated indicator of a 'wide spectrum' of health conditions. ${ }^{56}$ In the same way, the GHQ-12 showed a good performance as a screening instrument for common mental disorders and was not influenced by gender, age or educational level. ${ }^{36}$ Finally, the Nordic Questionnaire is recommended as a screening tool in occupational settings with a high sensitivity and specificity, especially for chronic or recurring low back pain. ${ }^{57}$ However, as a limitation, there were no diagnostic evaluations for any of the health outcomes included.

As in other cross-sectional studies, causal inference is not allowed, because we cannot assume that exposure occurred prior to the outcome. Additionally, the presence of the 'healthy worker' bias is common in many occupational studies and it may be present in our study as well. It is possible that teachers over 40 with more health complaints were retired or on sick leave.
Response in our study was moderate. One reason for this was that in some schools, even after several reminders and personal visits to the schools, the head teacher forgot to distribute the questionnaires to the teachers. One may speculate that these were schools had worse conditions compared with the participating schools. Therefore, the selection of teachers from schools with better conditions might have resulted in an underestimation of the true exposure and outcome prevalence. On the other hand, it is also possible that teachers with dissatisfaction about working or health conditions may have been more likely to answer the questionnaire, thereby overestimating the prevalences.

Due to difficulties in geographical access, our study excluded a priori schools with less than five teachers, most of which were located in remote and dispersed rural areas. Therefore, the generalisability of our study is limited to teachers working at schools with at least five teachers.

\section{CONCLUSIONS}

Our study describes the poor working conditions and high prevalence of mental and physical health outcomes in Bolivian school teachers, especially for those working in rural areas. The results support the influence of psychosocial factors on health conditions in teachers, calling attention to consider these aspects for educational and health policies. In Latin America, and in particular in Bolivia, it is necessary to have more precise information about working and health conditions through prospective studies or surveillance systems, in order to propose coordinated public strategies in the education and health sector that improve and support the sustainable development of the country.

Acknowledgements The authors express their gratitude to all the participants of the study for the cooperation. Special thanks to the Regional Office of Education of Unesco for Latin America and the Caribbean, Orealc/Unesco for the questionnaire instruments to assess teachers working condition. We thank Maeve Cook-Deegan for language editing support.

Contributors MTS-S participated in the design of the study acquisition of data, performed the statistical analysis and wrote the paper. AS participated in the design of the study and acquisition of data. KR and MP participated in the design of the study and helped to draft the manuscript. All authors revised the manuscript critically for important intellectual content and approved the final manuscript.

Funding This study was supported by the Network Funds 2015 through the Center for International Health of the University Hospital Munich (LMU) within the Higher Education Excellence in Development Cooperation (Exceed) program of the German Academic Exchange Service (DAAD) and the Federal Ministry for Economic Cooperation and Development (BMZ) - Germany.

Competing interests None declared.

Patient consent for publication Not required.

Ethics approval The study protocol was approved by the Bioethics Committee of the medical faculty of San Simón University, Cochabamba-Bolivia, the Regional Education Office in Chuquisaca and the authorities of every school.

Provenance and peer review Not commissioned; externally peer reviewed.

Data sharing statement The datasets used in this study are available from the corresponding author on reasonable request. 
Open access This is an open access article distributed in accordance with the Creative Commons Attribution Non Commercial (CC BY-NC 4.0) license, which permits others to distribute, remix, adapt, build upon this work non-commercially, and license their derivative works on different terms, provided the original work is properly cited, appropriate credit is given, any changes made indicated, and the use is non-commercial. See: http://creativecommons.org/licenses/by-nc/4.0/.

\section{REFERENCES}

1. Kourmousi N, Alexopoulos EC. Stress Sources and Manifestations in a Nationwide Sample of Pre-Primary, Primary, and Secondary Educators in Greece. Front Public Health 2016;4:73.

2. Hoglund WL, Klingle KE, Hosan NE. Classroom risks and resources: teacher burnout, classroom quality and children's adjustment in high needs elementary schools. J Sch Psychol 2015;53:337-57.

3. Hinz A, Zenger M, Brähler E, et al. Effort-Reward Imbalance and Mental Health Problems in 1074 German Teachers, Compared with Those in the General Population. Stress Health 2016;32:224-30.

4. Johnson S, Cooper C, Cartwright S, et al. The experience of workrelated stress across occupations. Journal of Managerial Psychology 2005;20:178-87.

5. Scheuch K, Haufe E, Seibt R, et al. Teachers' Health. Dtsch Arztebl Int 2015;112:347-56.

6. Van Droogenbroeck F, Spruyt B. To stop or not to stop: an empirical assessment of the determinants of early retirement among active and retired senior teachers. Res Aging 2014;36:753-77.

7. Harvey SB, Modini M, Joyce S, et al. Can work make you mentally ill? A systematic meta-review of work-related risk factors for common mental health problems. Occup Environ Med 2017;74:301-10.

8. Duchaine CS, Ndjaboué R, Levesque M, et al. Psychosocial work factors and social inequalities in psychological distress: a populationbased study. BMC Public Health 2017;17:91.

9. Siegrist J. Social reciprocity and health: new scientific evidence and policy implications. Psychoneuroendocrinology 2005;30:1033-8.

10. Knardahl S, Johannessen HA, Sterud T, et al. The contribution from psychological, social, and organizational work factors to risk of disability retirement: a systematic review with meta-analyses. BMC Public Health 2017;17:176.

11. Weyers S, Peter R, Boggild H, et al. Psychosocial work stress is associated with poor self-rated health in Danish nurses: a test of the effort-reward imbalance model. Scand J Caring Sci 2006;20:26-34.

12. Chandola T, Marmot M, Siegrist J. Failed reciprocity in close social relationships and health: findings from the Whitehall II study. $J$ Psychosom Res 2007;63:403-11.

13. Rugulies R, Aust B, Madsen IE. Effort-reward imbalance at work and risk of depressive disorders. A systematic review and metaanalysis of prospective cohort studies. Scand $J$ Work Environ Health 2017;43:294-306.

14. Gilbert-Ouimet M, Trudel X, Brisson C, et al. Adverse effects of psychosocial work factors on blood pressure: systematic review of studies on demand-control-support and effort-reward imbalance models. Scand J Work Environ Health 2014;40:109-32.

15. Dragano N, Siegrist J, Nyberg ST, et al. Effort-Reward Imbalance at Work and Incident Coronary Heart Disease: A Multicohort Study of 90,164 Individuals. Epidemiology 2017;28:619-26.

16. Erick PN, Smith DR. Musculoskeletal disorders in the teaching profession: an emerging workplace hazard with significant repercussions for developing countries. Ind Health 2015;53:385-6.

17. Koch $\mathrm{P}$, Schablon A, Latza U, et al. Musculoskeletal pain and effort-reward imbalance-a systematic review. BMC Public Health 2014;14:37

18. Siegrist J, Li J. Associations of Extrinsic and Intrinsic Components of Work Stress with Health: A Systematic Review of Evidence on the Effort-Reward Imbalance Model. Int $J$ Environ Res Public Health 2016;13:432.

19. Robalino M, Körner A. Condiciones de trabajo y salud docente. Estudios de casos en Argentina, Chile, Ecuador, México, Perú y Uruguay. Santiago, Chile: Oficina Regional de Educación de la UNESCO para América Latina y el Caribe, OREALC / UNESCO, 2005.

20. Subirats J, Nogales I. Maestros, escuelas, crisis educativa. Condiciones de trabajo docente en Bolivia. Santiago, Chile: UNESCO/OREALC, 1989.

21. Claro S, Bedregal P. Aproximación al estado de salud mental del profesorado en 12 escuelas de Puente Alto, Santiago, Chile. Revista medica de Chile 2003;131:159-67.

22. Aldrete Rodríguez MG, Pando Moreno M, Aranda Beltrán C, et al. Síndrome de Burnout en maestros de educación básica, nivel primaria de Guadalajara. Investigación en salud 2003(1).
23. Guzmán LR. Condiciones de trabajo docente: aportes de México en un estudio latinoamericano. Revista Electrónica Diálogos Educativos 2017;12:18-27.

24. Zamora-Díaz WJ, López-Noguero F, Cobos-Sanchiz D. Realidades del empleo docente en Nicaragua. Revista electrónica de investigación educativa 2016;18:191-205.

25. Cornejo Chávez R, Chávez RC. Condiciones de trabajo y bienestar/ malestar docente en profesores de enseñanza media de Santiago de Chile. Educação \& Sociedade 2009;30:409-26.

26. National Institute of Statistics (INE). $58.2 \%$ of teaching professionals are female. 2017. https://www.ine.gob.bo/index.php/principalesindicadores/item/562-58-2-de-profesionales-de-la-ensenanza-esmujer

27. Ministry of Education of Bolivia. Dossier of statistics and educational indicators. Regular education subsystem 2000-2014. La Paz, Bolivia. 2015.

28. Solis-Soto MT, Schön A, Solis-Soto A, et al. Prevalence of musculoskeletal disorders among school teachers from urban and rural areas in Chuquisaca, Bolivia: a cross-sectional study. BMC Musculoskelet Disord 2017:18:425.

29. National Institute of Statistics (INE). Population projections by department and municipality, 2012-2020 [Internet]. 2016;2016. www. ine.gob.bo

30. United Nations Development Programme. Human Development Report. 2016;2016.

31. Almodóvar A, Pinilla F. VI National Survey of Working Conditions (ENCT). España: National Institute of Safety and Health at Work (INSHT), 2007.

32. Siegrist J, Li J, Montano D. Psychometric properties of the effortreward imbalance questionnaire. Department of Medical Sociology FoM: Duesseldorf University, 2013.

33. Juárez-García A, Vera-Calzaretta A, Blanco-Gomez G, et al. Validity of the effort/reward imbalance questionnaire in health professionals from six Latin-American countries. Am J Ind Med 2015;58:636-49.

34. Vilagut G, Ferrer M, Rajmil L, et al. [The Spanish version of the Short Form 36 Health Survey: a decade of experience and new developments]. Gac Sanit 2005;19:135-50.

35. Laaksonen M, Rahkonen O, Martikainen P, et al. Associations of psychosocial working conditions with self-rated general health and mental health among municipal employees. Int Arch Occup Environ Health 2006;79:205-12.

36. Goldberg DP, Gater R, Sartorius N, et al. The validity of two versions of the GHQ in the WHO study of mental illness in general health care. Psychol Med 1997;27:191-7.

37. Burrone MS, Abeldaño A, Lucchese M, et al. [Psychometric properties and reliability of the general health questionnaire(GHQ-12) for adult patients in primary care centers in Cordoba, Argentina]. Rev Fac Cien Med Univ Nac Cordoba 2015;72:236-42.

38. Kuorinka I, Jonsson B, Kilbom A, et al. Standardised Nordic questionnaires for the analysis of musculoskeletal symptoms. Appl Ergon 1987;18:233-7.

39. Liu Y, De A. Multiple Imputation by Fully Conditional Specification for Dealing with Missing Data in a Large Epidemiologic Study. Int J Stat Med Res 2015;4:287-95.

40. World Health organization. Standards and Operational Guidance for Ethics Review of Health-Related Research with Human Participants. Geneva, Switzerland: WHO Document Production Services, 2011.

41. Witvliet MI, Kunst AE, Stronks K, et al. Variations between world regions in individual health: a multilevel analysis of the role of socioeconomic factors. Eur J Public Health 2012;22:284-9.

42. Seibt R, Spitzer S, Druschke D, et al. Predictors of mental health in female teachers. Int J Occup Med Environ Health 2013;26:856-69.

43. Nomoto M, Hara A, Kikuchi K. Effects of long-time commuting and long-hour working on lifestyle and mental health among school teachers in Tokyo, Japan. J Hum Ergol 2015;44:1-9.

44. Perreira KM, Telles EE. The color of health: skin color, ethnoracial classification, and discrimination in the health of Latin Americans. Soc Sci Med 2014;116:241-50.

45. Falk H, Skoog I, Johansson L, et al. Self-rated health and its association with mortality in older adults in China, India and Latin America-a 10/66 Dementia Research Group study. Age Ageing 2017;46:932-9

46. Darboe A, Lin IF, Kuo HW. Effort-reward imbalance and self-rated health among Gambian healthcare professionals. BMC Health Serv Res 2016:16:125.

47. Koch P, Kersten JF, Stranzinger J, et al. The effect of effort-reward imbalance on the health of childcare workers in Hamburg: a longitudinal study. J Occup Med Toxicol 2017;12:16.

48. DeSalvo KB, Bloser N, Reynolds K, et al. Mortality prediction with a single general self-rated health question. A meta-analysis. J Gen Intern Med 2006;21:267-75. 
49. Moreno X, Albala C, Lera L, et al. The role of gender in the association between self-rated health and mortality among older adults in Santiago, Chile: A cohort study. PLoS One 2017;12:e0181317.

50. Falconer J, Quesnel-Vallée A. Pathway from poor self-rated health to mortality: explanatory power of disease diagnosis. Soc Sci Med 2017; 190:227-36.

51. Stansfeld S, Candy B. Psychosocial work environment and mental health-a meta-analytic review. Scand J Work Environ Health 2006;32:443-62.

52. Erick PN, Smith DR. A systematic review of musculoskeletal disorders among school teachers. BMC Musculoskelet Disord 2011;12:260.
53. Bugajska J, Zołnierczyk-Zreda D, Jędryka-Góral A, et al. Psychological factors at work and musculoskeletal disorders: a one year prospective study. Rheumatol Int 2013;33:2975-83.

54. Zamri EN, Moy FM, Hoe VC. Association of psychological distress and work psychosocial factors with self-reported musculoskeletal pain among secondary school teachers in Malaysia. PLoS One 2017;12:e0172195.

55. Chirico F. Job stress models for predicting burnout syndrome: a review. Ann Ist Super Sanita 2016;52:443-56.

56. Jylhä M, Volpato S, Guralnik JM. Self-rated health showed a graded association with frequently used biomarkers in a large population sample. J Clin Epidemiol 2006;59:465-71.

57. Takekawa KS, Gonçalves JS, Moriguchi CS, et al. Can a selfadministered questionnaire identify workers with chronic or recurring low back pain? Ind Health 2015;53:340-5. 